\title{
Shared variability in body shape characters at growing phase of indigen ous piglets
} D. M. Ogah

Animal Science Department, Faculty of Agriculture, Nasarawa State University Keffi Shabu

Lafia campus,

mosesdogah@yahoo.com

$+2348065303418$

\begin{abstract}
Body measurement traits, body length (BL), rump height (RH), rump length (RL), rump width (RW), shoulder width $(S W)$, wither height $(W H)$, heart girth $(H G)$, and flank length (FL) of 52 piglets of indigenous breed, managed under traditional system were obtained at birth and at weaning, to evaluate the sources of shared variability and efficiency of weight determination. Factor analysis reveals four factors accounting for $89.53 \%$ at birth and three factors accounting for $73.52 \%$ at weaning. Most common variability in body dimension at birth and at weaning could be accounted for by factors representing general size and RL in both cases. Body conformation "shape" was controlled by common and unique factors at both ages. Amount of variation associated with shape characters increased with advancing age and accuracy of weight estimation decreased with increase in age.
\end{abstract}

Keywords: Body shape characters, growing phase and piglets

\section{Introduction}

The relationship between physical measurements such as body dimensions, body size and weight of an animal is a valuable tool in livestock selection. Size and shape of various body parts are the major determinants of the overall size and shape of a live animal (Shahin, 1999, Shahin and Hassan, 2000 and Ogah, 2011). The production of indigenous pigs has remain valuable as an alternative source of food and protein (Okorie, 1978). Efforts have so far been made to improve their potentials particularly their breeding value, (Adebambo 1985, , Adebambo 1991; Adebambo and Dettmers, 2000). Despite that, it has not really impacted on the pig population of the entire country as most of the work were being carried out in south western part of the country even with the appreciable population of the animal around the central and north eastern part. To be able to confront this challenges to improve the performance of pigs, it requires a systematic approach thus, this necessitate the evaluation of its performance at growing phase to enable understanding of adult value and to suggest ways of improvement. A number of studies have used factor analysis to eliminate redundancies from sets of interrelated variables and to extract and identify covariant variable sets that are statistically unrelated as well as extracting variability index in relation to weight development (Shahin,1999, Shahin and Hassan, 2000). These has helped as a criteria for improvement of economic traits as well as for selection (Shahin and Hassan, 2002).

The objective of the study was to assess the main sources of shared variability and describe body conformation and prediction of weight at birth and at weaning period in indigenous piglets.

\section{Materials and Methods}

The animals used in this experiment were 52 piglets from ten sows raised semi extensively by native farmers in Lafia, Nasarawa State, Nigeria. The data was 
generated between April to September 2009. The traits measured include body weight, body length, rump height, rump length, rump width, shoulder width, wither height, heart girth, and flank length measured at birth period and the same traits measured at weaning six weeks period as described by (Subalini et al., 2010).

\section{Statistical analysis}

The data were subject to a factor analysis procedure (SAS, 1999). The descriptive statistics and correlation between traits was evaluated earlier (Ogah et al., 2011). The main source of shared variation among the interdependence of body measurements (p) was expressed in terms of fewer mutually uncorrelated common factors $\mathrm{F} 1$, $\mathrm{F} 2, \mathrm{~F} q$ (where $q<p$ ) than the original measurements( Darton, 1980). The first factor contained the greatest portion of the original variation and in a morphometric application of factor analysis, it was designated as a general size factor. Subsequent factors were mutually orthogonal to those preceding and to one another and contained less variation. The model used is as follows:

$\mathrm{X}=\mathrm{LF}+\mathrm{U}$

where $\mathrm{X}=a p^{\prime} 1$ is a vector observational variables; $\mathrm{L}=a p^{\prime} q$ a matrix of factor loading 'factor - variate correlations, the degree of correlation of the variable with factor' (the pattern matrix); $\mathrm{F}=a q^{\prime} 1 \mathrm{a}$ vector of factors (non-observable) and $\mathrm{U}=a p^{\prime} 1$ a vector of the specific 'unique' factor.

The total variance of a variable was equal to unity and can be written as the sum

of common variance 'communalities' and unique variance 'uniqueness'. The communality

represented the portion of the variable variance accounted for by all common

factors and the uniqueness, represented the portion of the variable variance not ascribable

to its correlation with other variables. A build up stepwise multiple regression was used to predict body weight from the live measurements. Attaining the 5\% level of significance was the predetermined criterion for entering the independent variables. Their sequence of retention followed a descending order for the amount of variance explained. The program terminated when the last independent variable entering the equation had an insignificant regression coefficient.

Table1: Explained variation associated with rotated factor analysis along with communalities of each variable

\begin{tabular}{llllllllll}
\hline & \multicolumn{3}{c}{ At Birth } & \multicolumn{5}{c}{ At Weaning } \\
Communality & F1 & F2 & F3 & F4 & & F1 & F2 & F3 \\
\hline Body length & -.514 & -.145 & .671 & -.034 & 736 & -.311 & .135 & -.593 & .467 \\
Rump height & -.206 & .780 & .365 & .399 & .943 & .464 & -.330 & .584 & .665 \\
Rump length & .831 & .339 & .329 & -.016 & .914 & .850 & .268 & .213 & .839 \\
Rump width & .482 & .710 & -.224 & .230 & .840 & .836 & .229 & .176 & .782 \\
Shoulder width & .165 & -242 & .551 & .739 & .935 & -.741 & .515 & .277 & .890 \\
Wither height & .446 & -.505 & .599 & .362 & .965 & .514 & -.269 & .458 & .547 \\
Heart girth & .811 & .285 & -.111 & -.352 & .875 & .514 & .695 & -.203 & .788 \\
Flank length & -.627 & .551 & .508 & -.007 & .955 & -.522 & .650 & .458 & .903 \\
\% of variance & 31.31 & 24.61 & 20.93 & 12.68 & & 38.53 & 18.67 & 18.67 & \\
\hline
\end{tabular}




\section{M. Ogah}

\section{Results and Discussion}

The explained variation associated with rotated factor analysis along with their communalities for each variable is presented in Table1. For the body measurements at birth and at weaning of the indigenous pigs. At birth four common factors have been identified which contribute from $73.6 \%$ to $96.5 \%$ of the original eight variables, leaving 26.4 to $3.5 \%$ to the special factors, the first factor F1 (General size) loaded highly and positively for rump length and heart girth and negative for flank length with the rest factors as rump height, body length and shoulder width respectively. These factors accounted for $31.3,24.6,20.9$ and $12.7 \%$ variations respectively. At weaning three common factors were extracted contributing from 46.7 to $90.3 \%$ of the original eight variables leaving 53.3 to $9.7 \%$ to the special factor. High loading of the first factor was achieved by rump length, rump width and shoulder width while the rest were heart girth and body length and accounted for 38.3, 18.7 and $16.3 \%$ total variation. The communalities for various variables (The variance of a variable was partitioned into a" common" portion communality shared with some or all of the other variables and "uniqueness" portion unique to that particular variable. It indicated that $47 \%$ to $96.5 \%$ of the variation both at birth and at weaning were brought about by common factors whereas 3.5 to $53 \%$ of their variation were contributed by unique factors specific to each trait. At birth it ranged from 73.6 for body length to 96.5 for shoulder width,

Table 2: Stepwise multiple regression of live weight on original body meas urements at birth and at weaning

\begin{tabular}{|c|c|c|c|c|c|c|}
\hline Step & independent variable & intercept & $\begin{array}{c}\text { Regression } \\
\text { Coeff. }\end{array}$ & $\mathrm{SE}$ & $\mathrm{R}^{2}$ & VIF \\
\hline & Predictor & & & & & \\
\hline & At Birth & & & & & \\
\hline 1 & $\mathrm{BL}$ & -.740 & .090 & .02 & .53 & 1.000 \\
\hline \multirow[t]{2}{*}{2} & $\mathrm{BL}$ & -2.214 & .085 & .01 & .65 & 1.013 \\
\hline & RW & & .174 & .05 & & 1.013 \\
\hline \multirow[t]{3}{*}{3} & $\mathrm{BL}$ & -1.873 & .094 & .01 & .82 & 1.046 \\
\hline & RW & & .259 & .04 & & 1.195 \\
\hline & $\mathrm{HG}$ & & -.060 & .01 & & 1.232 \\
\hline \multirow[t]{4}{*}{4} & BL & -3.120 & .099 & .01 & .95 & 1.051 \\
\hline & RW & & .257 & .02 & & 1.195 \\
\hline & $\mathrm{HG}$ & & -.068 & .01 & & 1.262 \\
\hline & WH & & .062 & .01 & & 1.036 \\
\hline \multirow[t]{6}{*}{5} & $\mathrm{BL}$ & -2.679 & .088 & .20 & .98 & 1.392 \\
\hline & RW & & .226 & .00 & & 1.382 \\
\hline & $\mathrm{HG}$ & & -.093 & .02 & & 2.943 \\
\hline & WH & & .069 & .01 & & 1.093 \\
\hline & $\mathrm{RL}$ & & .048 & .01 & & 1.997 \\
\hline & At Weaning & & & & & \\
\hline 1 & $\mathrm{RH}$ & -6.311 & .475 & .09 & .48 & 1.000 \\
\hline \multirow[t]{2}{*}{2} & RH & -19.710 & .588 & .07 & .74 & 1.096 \\
\hline & BL & & .423 & .08 & & 1.096 \\
\hline
\end{tabular}

$\mathrm{BL}=$ Body length, $\mathrm{RW}=$ rump width, $\mathrm{HG}=$ heart girth, $\mathrm{WH}=$ wither height, $\mathrm{RH}=$ rump height, $\mathrm{RL}=$ rump length. 
Table 3 Multple regression of live weight on orthogonal traits at birth and at weaning

\begin{tabular}{|c|c|c|c|c|c|c|}
\hline Step & $\begin{array}{l}\text { independent } \\
\text { variable }\end{array}$ & intercept & Reg. Coeff & se & $\mathrm{R}^{2}$ & VIF \\
\hline \multicolumn{7}{|c|}{ At birth } \\
\hline 1 & FC4 & 1.320 & .091 & .022 & .37 & 1.000 \\
\hline \multirow[t]{2}{*}{2} & FC4 & 1.320 & .091 & .021 & 47 & 1.000 \\
\hline & $\mathrm{FC} 1$ & & .047 & .021 & & 1.000 \\
\hline \multicolumn{7}{|c|}{ At weaning } \\
\hline & $\mathrm{FC} 1$ & 4.553 & .011 & .066 & .33 & 1.000 \\
\hline & $\mathrm{FC} 2$ & & -.042 & .066 & & 1.000 \\
\hline & $\mathrm{FC} 3$ & & .108 & .066 & & 1.000 \\
\hline
\end{tabular}

while at weaning from 46.7 for body length to 90.3 for flank length. At both ages Body length (skeletal dimensions) had the lowest communalities with the greatest uniqueness. Similarly skeletal wither height and flank length (skeletal dimension) had the highest communalities with lower uniqueness at both ages. Shahin et al.(1993) working with Egyptian buffalo bull found out that communalities for skeletal dimension were higher than flesh dimensions. Indicating the relevance skeletal dimension in size description thus its importance in body component determination.

Stepwise multiple regression of the body weight on independent body shape characters is outline in Table 2. At birth, predicting live body weight from the independent body measurements shows that BL accounted for $53 \%$ of the variability in body weight, on inclusion of $\mathrm{RW}, \mathrm{HG}, \mathrm{WH}$ and $\mathrm{RL}$ the proportion of explained variance increased from 65 to $98.6 \%$. At weaning RH accounted for $48 \%$ variability and increases to $74 \%$ on addition of BL . The significant of these two traits (BL and $\mathrm{RH}$ ) in weight were also reported by (Shahin and Hassan, 2000 and Yakubu and Ayoade, 2009). The result also variation traits associated with weight prediction with age, suggesting that as the animal advances in age fewer shape characters will be involved in weight determination and the efficiency of prediction decreases with age (Shahin et al., 2002).

Multiple linear regression of body weight on independent orthogonal trait derived from factor scores are outlined in Table 3. Stepwise approach was adopted for the traits at birth which accounted for $47 \%$. At weaning the factor score could not go into the stepwise rather simple linear backward and forward approach was adopted and accounted for $33 \%$. From all indications stability in weight estimation was best using original traits than orthogonal traits. This shows that use of factor score cannot be a reliable instrument in determination of body traits in indigenous pig.

\section{Conclusion}

This result has shown that increase in amount of variation associated with shape characters in indigenous piglets is associated with advancement in age, number of variables involved on weight determination decreases with age, similarly, original traits are best predictor of weight than independent orthogonal factors 
derived from factor analysis.

\section{References}

Adebambo, O.A. 1991. Research Bulletin for Pig Production, Breeding and Feeding. IAR \& T Research Bulletin for Farmers. $21 \mathrm{pp}$.

Adebambo, O. A and Dettmers, A. 1978. Selection for reproductive rate in Indigenous sows .Niger J. Genet 2: 97 103

Adebambo, O. A., 1985. Crossbreeding the Nigerian Indigenous Pigs .1:Effects of crossing and early weaning on sow performance. Turri Alba 35(3): 221-227.

Darton, R. A. 1980. Rotation in factor analysis. Statistician 29:167-194.

Ogah, D. M. 2011. Shared variability of body shape characters in adult Muscovy duck. Biotechnology in Animal Husbandry 27(2) 189-196.

Ogah, D. M., Yusuf, N. D and Ari, M. M. 2011. Path coefficient model for assessment of weight using linear traits at birth and at weaning in Nigeria indigenous pig. In Proc.of 34th Annual Conference of Tanzania Society of Animal Production. 2011.

Okorie, J. U. 1978. A guide to livestock production in Nigeria. Macmillian Ltd.London 155pp.

SAS, 1999. SAS/STAT user 's guide Release 8.0 SAS Inst. Inc Cary NC
USA.

Shahin, K.A.,1999. Sources of shared variability in muscle and fat weight distribution in Pekin ducklings, Ann. Zootech. 48 (1999) 59-66.

Shahin, K. A. and Hassan, N. S. 2000. Sources of shared variability among body shape characters at marketing age in newzealand white and Egyptian rabbit breeds. Annal Zootech. 49:435445

Shahin, K.A. , Soliman, A. M. and Moukhtar, A. E.1993. Sources of shared variability for Egyptian buffalo body shape (conformation) Indian journal of Animal Science 65:323-334.

Shahin, K A. and Hassan, N. S. 2002. Changes in sources of shared variability of body size and shape in Egyptian local and Newzealand White breeds of rabbit during growth.Arch. Tierz Dummerstorf 45:269-277.

Subalini, E., Silva G.L.L.P. and Demetawewa, C.M.B. 2010 . Phenotypic characterization and production performance of village pigs in Sri Lanka. Tropical Agricultural Research 21(2)198-208.

Yakubu, A. and Ayoade, J. A. 2009. Application of principal component factor analysis in quantifying size and morphological indices of domestic rabbit. Int. J. Morph 22(4) 1013-1017 